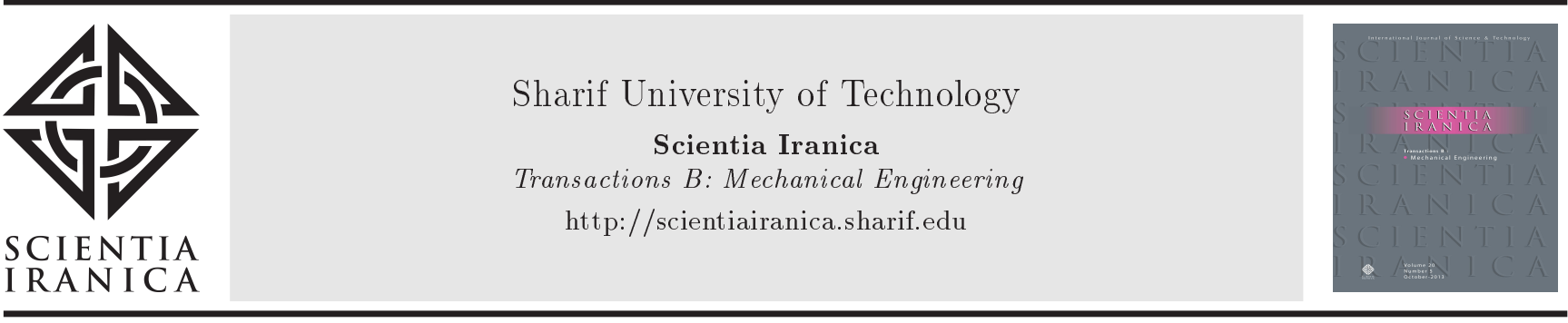

Research Note

\title{
An experimental study of water freezing in cylindrical stagnation flow
}

\author{
A. Shokrgozar Abbasi* and M. Najafian \\ Department of Mechanical Engineering, Payame Noor University, Moallem 71 Street, Mashhad, Iran.
}

Received 28 November 2020; received in revised form 18 January 2021; accepted 15 March 2021

\author{
KEYWORDS \\ Experimental \\ investigation; \\ Water solidification; \\ Stagnation flow; \\ Cylindrical freezing; \\ Ice thickness.
}

\begin{abstract}
In this experimental study, we investigate the process of freezing of water in cylindrical stagnation flow to compare the degree of agreement of the results of the present study with the theory solution. We are also looking for a way to determine the flow regime. The water impinges vertically on a cold flat plate while the water outlet section is cylindrical. The water starts to freeze when the substrate plate is sufficiently cold. The effects of distance between the outlet and the substrate plate, magnitude of the flow strain, water temperature, and the plate involved in ice formation, and most importantly, the final thickness of the ice have been investigated. We have compared the results with a numerical solution. The results show a good agreement in the middle of the ice thickness curve. As a result, the speed of ice formation is very high at first and declines sharply with a steep slope. More importantly, a particular definition is employed for achieving the regimes (laminar, turbulent, or transitional) in stagnation flow. According to the results, the ice thickness in laminar flow is greater than that in turbulent one.

(C) 2021 Sharif University of Technology. All rights reserved.
\end{abstract}

\section{Introduction}

Freezing is an important phenomena in science and industry. The industry can use the high latent heat of phase change as a reserve. Correspondingly, in semiconductor production, controlling the freezing phase increases the quality of semiconductors, which is also applicable in the nuclear industry. The speed and penetration of ice during the freezing of all kinds of food also play a significant role in maintaining their quality and shelf life. Ice formation and its conditions on the nose and wings of aircraft and projectiles, such as missiles, must also be carefully assessed. Therefore,

\footnotetext{
*. Corresponding author. Tel.: $098513868388 \%$; Fax: 0985138451620

E-mail address: shokrgozar.ali@gmail.com (A. Shokrgozar Abbasi)
}

doi: $10.24200 /$ sci. 2021.57134 .5082 a better understanding of this critical phenomenon requires proper and accurate insight into freezing. So far, freezing in the boundary layer has been studied more frequently than freezing in stagnation flow, while a study of both areas is required to complete the study on freezing of a moving object. There are few studies on freezing, but they are very valuable. Investigations related to freezing and stagnation flow are: Stefan [1] solved the classic problem of ice formation in polar seas using the analytical method. Goodrich [2] investigated the heat flux of phase change in one-dimensional issues. Sparrow et al. [3] experimentally investigated the behavior of the fluid, natural convection in the border of liquid and solid phases. Lacroix [4] considered numerical methods for solving the heat transfer during melting of a pure material from an isothermal wall. Yeoh et al. [5] conducted a three-dimensional numerical study for free convection with phase change in a crosssection of a rectangular channel. Hadji and Schell [6] investigated the possibility of combining hydrodynamic 
with the behavior of the solid-liquid boundary of fluids, which is located between two freezing insulated plates. Hanumanth [7] presented a method for calculating time-dependent heat flux caused by natural convection during fluid freezing between two isolated plates. Curtis et al. [8] provided an integrated model for continuous phase change issues. Trapaga et al. [9] studied the freezing of molten metal droplets on a rigid plate, and Watanabe et al. [10] compared the numerical modeling and laboratory results deformation and freezing of a liquid droplet on a cold plate. Marchi et al. [11] presented an evaluation of an existing transformation model and freezing of a drop impinging on the substrate plate. Weidman and Mahalingam [12] investigated the flow of viscous fluid produced by the axisymmetric stagnation flow on a flat plate that, at its coordinates, has damped oscillatory motion. Shokrgozar Abbasi and Rahimi [13] investigated the heat transfer and flow in axisymmetric three-dimensional viscous stagnation flow. They [14] also considered heat transfer and flow in the axisymmetric three-dimensional system with suction and blowing in stagnation flow. They obtained the characteristics of velocity, pressure, temperature, and stress in [13,14]. Shokrgozar Abbasi et al. [15] presented the exact solution of the unsteady heat transfer in stagnation flow on a heated plate. If the common two-phase boundary has uniform heat transfer, the surface of the common boundary will be a flat plate; also, acceleration of the fluid flow is variable in the field of solidification. In this case, the motion of the surface of the common two-phase boundary can be simulated with an accelerating plate towards the flow, so the problem of moving this accelerating plate with variable acceleration must be solved. Also, the minimum thickness of the boundary layer occurs at the maximum value of the plate velocity. The plate velocity speed plays a significant role in determining boundary layer thickness and acceleration plays a secondary role in the two-dimensional and axisymmetric stagnation flow on an accelerated flat plate $[16,17]$. Brattkus and Davis [18] considered stagnation flow solidification of an inviscid fluid that freezes at the shared liquid, and solid border. Rangel and Bian [19] solved the problem of solidification of inviscid fluid in stagnation flow. Lambert and Rangel [20] investigated freezing in the sub-cooled liquid stagnation region (freezing point) in the two-dimensional Cartesian coordinate system. Yoo [21] considered viscous fluid phase change in stagnation flow. Shokrgozar Abbasi and Rahimi [22] presented the solidification of incompressible fluid in two-dimensional stagnation flow. Shokrgozar Abbasi [23] also showed that increasing the Prandtl number to 10 times or increasing the thermal diffusivity to 2 times will cause the final frozen thickness to be reduced by nearly half, while the Stefan number does not affect the thickness and only affects the freezing time in axisymmetric stag- nation flow. Alizadeh et al. [24] investigated the steadystate viscous flow and heat transfer in the vicinity of an unaxisymmetric stagnation-point of an infinite stationary cylinder. Adil [25] showed that the magnetic field can reduce the thickness of the velocity boundary layer near the stagnation point flow. Also, the increase of Brownian motion parameter and the thermophoresis parameter cause the thickness of the thermal boundary layer to be smaller than the velocity. Regarding the stagnation point flow and porous medium, Imtiaz et al. [26] investigated the effects of a ferrofluid flow on a variable thicked sheet. The results show the effect of several parameters on speed and temperature. Rahimi and Mozayeni [27] investigated the unsteady threedimensional axisymmetric stagnation-point flow of a viscous compressible. Waini et al. [28] showed that the heat transfer rate of the hybrid nanofluid is higher than that of the conventional nanofluid and the conventional fluid in the stagnant flow. Also, the nanoparticles and larger Reynolds numbers increase the heat transfer and skin friction coefficients. Shokrgozar Abbasi and Ghayeni [29] showed the ultimate frozen thickness and the rate of solidification for different values of nondimensional Prandtl and Stefan numbers for saturated air temperatures in two-dimensional stagnation flow. Regarding the stagnation point flow and magnetohydrodynamics, Narender et al. [30] investigated the effects of radiation in the presence of magnetic field and heat generation/absorption using a Casson nanofluid. Maqbool et al. [31] modeled a ferrofluid stagnation flow over a stretched surface with Ohmic heating and dissipation. The results include the effect of different pertinent flow parameters on temperature, velocity, Nusselt number and skin friction coefficient; however, the aim of this experimental study is to determine the degree to which theoretical findings are consistent with what is happening in practice, and to find a way to determine the flow regime. Regarding the numerical solution, it is assumed that the output flow from the nozzle is fully developed, which is not entirely possible in practice. Of course, we minimize the nozzle length and shape it to minimize the effects of viscosity on the nozzle output to approach the fully developed flow and prevent free jet flow. Also, gravity acceleration causes a slight deviation of stagnation flow. This experimental study can determine the correctness of the assumptions considered in the numerical solution. To this end, a device has been prepared and experiments are carried out on different strains and various distances of the water output section from the cold plate. The results are compared with numerical solutions.

\section{Experiment description}

To conduct the study, a device has been prepared, which is shown in Figure 1(a) to (d). 


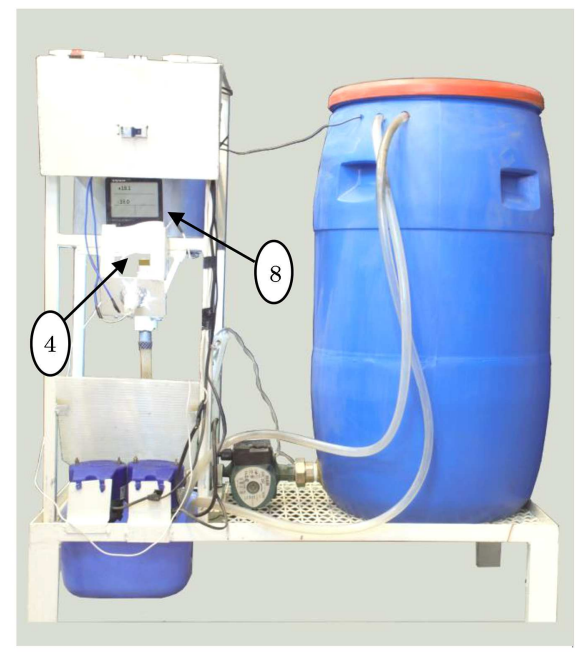

(a)

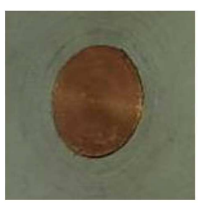

(c)

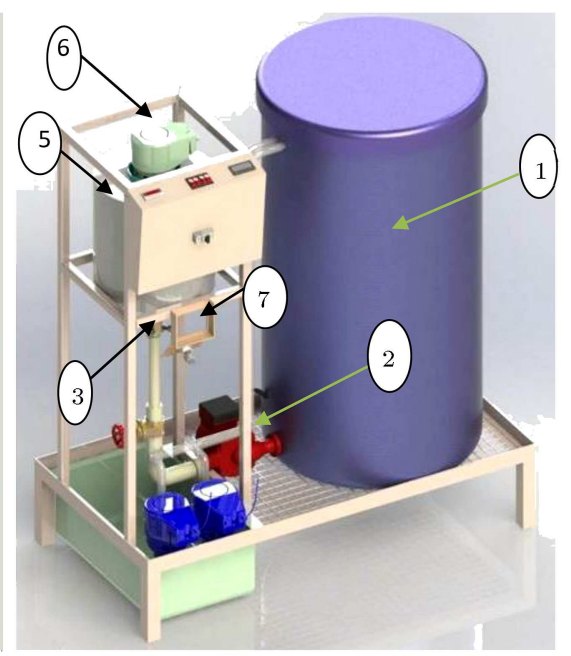

(b)

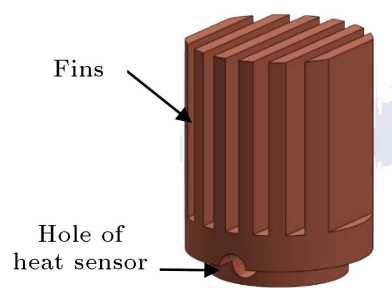

(d)

Figure 1. (a) Real image of the device used in this experimental study. (b) Schematic of the device and its components. (c) Real image of the top of a circular plate on which ice forms (4). (d) Schematic of the circular plate with it fins and a hole where the sensor is installed.

It should be noted that in this study the unit of degrees Celsius is considered to measure the temperature by related equipment. The device is composed of:

1. A source of the primary water;

2. Primary water pump;

3. Nozzle;

4. Circular plate;

5. The refrigerant inside the insulated tank, containing a mixture of water, ethylene glycol, and liquid nitrogen;

6. Stirring refrigerant pump;

7. Measurements and monitoring equipment;

8. Filming equipment.

The main source of water (Table 1) should change the temperature in contact with the circular copper cold plate and be cooled by it. This water is pumped (2) upwards by a tube up to a radius of $R=13 \mathrm{~mm}$. At the outlet of the pipe, a nozzle (3) with a radius of $R=8 \mathrm{~mm}$ is placed in the opposite direction to the gravity of the earth, which exerted vertically on the cold plate. The stagnation flow occurs on the circular copper cold plate. Note
Table 1. Water properties at $0^{\circ} \mathrm{C}$

\begin{tabular}{ccc}
\hline Density & 999.88 & $\mathrm{~kg} / \mathrm{m}^{3}$ \\
Kinematic viscosity & $1.792^{*} 10-6$ & $\mathrm{~m}^{2} / \mathrm{s}$ \\
Specific heat capacity & 4.219 & $\mathrm{~kJ} /(\mathrm{kg} . \mathrm{K})$ \\
Thermal conductivity & 0.561 & $\mathrm{~W} /(\mathrm{m} . \mathrm{K})$ \\
Prandtl number & 13.67 & - \\
Latent heat & 333.55 & $\mathrm{~kJ} / \mathrm{kg}$ \\
\hline
\end{tabular}

that the intention of the nozzle in this paper is merely the output of a tube opening with a length $L=18 \mathrm{~mm}$ and a constant diameter. The difference in the pipe diameter in the nozzle makes it possible to achieve the minimum formation of a laminar flow profile. Also, the minimum distance from the nozzle to the cooling plate is necessary to avoid free jets. The water that does not freeze on the cold plate slips down its sides and exits the circuit. In this case, gravity slightly accelerates water flow after entering the atmosphere and changes its velocity. If the fluid flow is horizontal, the effect of gravity will cause the cylindrical flow to be non-axisymmetric, and we will not have a stagnation flow. The slight effect of gravity, both downward and upward, is equal. Of course, a small change in speed caused by gravity acceleration is an inevitablefactor which causes a slight deviation of stagnation flow in the experimental study. However, when the fluid flow 
is upwards, the lid of the refrigerant tank can be left open, and ice cubes can be easily seen. In this case, it is also practical to keep the temperature constant because when the volume of ice cubes decreases, it is easily possible to add liquid nitrogen from above. Furthermore, it is easier to stir the fluid mixture. In Figures 1(c) and (d), the circular plate (4) consists of a heat sink, a heat sensor hole, and a round plate made from one piece of copper. Obviously, the size of the substrate plate has nothing to do with the results. The minimum size is selected so that without producing large amounts of refrigerant, the results could be seen clearly. This plate with a circular cross-section of radius $R=9.5 \mathrm{~mm}$ on one side and with its fins, is cooled by the refrigerant fluid (5), on the other hand, it causes water freezing as simple as water cooling. By adding a certain amount of ethylene glycol (as antifreeze), a specific freezing point temperature can be set for the refrigerant fluid. In this case, a balance is established between solid and fluid. As long as this equilibrium is maintained, i.e. the pieces of ice are floating in the fluid, the temperature of the fluid remains constant. The temperature of the refrigerant $-18^{\circ} \mathrm{C}$ is selected. Therefore, the temperature of the cold plate is very close to $-18^{\circ} \mathrm{C}$ because the heat transfer coefficient of copper is much higher than that of ice $\left(\mathrm{Cu}: 385 \mathrm{wm}^{-1} \mathrm{k}^{-1}\right.$, Ice: $\left.1.6385 \mathrm{wm}^{-1} \mathrm{k}^{-1}\right)$ [32]. Stirring the refrigerant pump (6) makes the temperature of the coolant fluid uniform and increases the heat transfer between the coolant fluid and the circular plate. Measurements and monitoring equipment (7) consist of an inlet water temperature sensor, a circular substrate temperature sensor, an ambient air temperature sensor, a refrigerant temperature sensor, and a screen monitor that displays the temperatures. Particular arrangements are devised for the installation of temperature sensors. An LM35 (LM35 is a temperature measuring device having an analog output voltage proportional to the temperature. It provides output voltage in Centigrade (Celsius). It does not require any external calibration circuitry.) temperature sensor is installed at the nearest distance to the cold substrate flat plate with the maximum contact coefficient so that their speed and accuracy are maximized. For example, the sensor pod diameter has a tolerance of less than $0.5 \mathrm{~mm}$, and the sensor is inserted forcefully into the pod. At the same time, silicon paste has been used to fill the probable pores between the pods and the sensor and to increase the maximum contact coefficient. The installation site of this pod is less than $1 \mathrm{~mm}$ from its surface, where freezing occurs. First, the cold plate is stabilized at the desired temperature, and then the water flow pump is turned on. The temperature is measured at each instant, and various desired points, including the inlet water, the refrigerant fluid, the refrigerated substrate plate, the ambient air temperature. Similar to the particle image velocimetry method (PIV), the filming is performed at 250 frames per second by the filming equipment (8). In this paper, the measurement of speed was not necessary, because we focused on the evolution of ice thickness growth at different times. This method provides good accuracy for measuring thickness. This speed is fast enough compared to the total time of about 10 minutes, but if the ice level changes are considered at the very first moments of the start of ice formation, filming speed will not be enough, no matter how high it will rise, because the speed of freezing at the initial moments is too much. The numerical data $[22,24]$ shows that the total time was about 10 minutes, and the icing speed at the initial moment was $4.5 \mathrm{~m} / \mathrm{s}$, which reduced quickly.

\section{Experimental method}

The following steps are followed to conduct the study. First, the distance between the nozzle and the surface of the refrigerator plate is set to a specific value, and its vertical and center directions are controlled by the plate as follows. The bottom plate of the nozzle is leveled. With the help of a laser, the three-pin mechanism of the nozzle installation, including three adjusting screws, is adjusted to be completely perpendicular to the horizontal plane. The water reservoir had an appropriate time in the test environment to make its water temperature consistent with the ambient temperature. Because the volume of the reservoir was large and its temperature difference with the environment was negligible, the water temperature of the reservoir remained constant until the end of the test. The water level of the tank is maintained constant, which is important for stabilizing the flow rate. The refrigerant fluid, which contains water and antifreeze, is cooled by liquid nitrogen. We added enough antifreeze so that at the desired temperature, the water could be freezed. By adding liquid nitrogen the amount of ice will be increased, so the refrigerant temperature will remain constant. Conversely, the amount of ice decreases when we heat the refrigerant. So, this two-phase mixture helps to stabilize the temperature of the refrigerant. Using this method, even if heat is suddenly absorbed in the beginning of the test, the temperature of the refrigerant remains almost unchanged. So, in the presence of ice, there is sufficient time to increase the amount of liquid nitrogen in the solution, with only a tiny temperature change.

Furthermore, if an excessive amount of liquid nitrogen is added, more ice will be produced without lowering the water temperature. The temperature of the surface of the cold copper plate is reduced to the desired temperature by this two-phase fluid. The copper plate transfers heat from the water main to this refrigerant liquid. The copper plate was surrended by a PVC (a synthetic thermoplastic material made 
by Polymerizing Vinyl Chloride) plate, and there was no possibility of freezing water in this region. The copper plate was inside the hole in the PVC plate. The copper plate has fins where the refrigerant fluid is, and turbulent flow hits the fins at high speed and cools them. As a result, all temperatures and water flow rates are carefully stabilized, and the obtained results are as accurate as possible. The main pump is then switched on, and water flow is adjusted to a specified value by a globe valve. The turbulent pump flushed the refrigerant liquid flow to provide maximum heat transfer rates. In this experiment, two cameras were used to record the events. The first camera is turned on record and it is focused on the cold copper plate. The second camera was responsible for recording temperatures at every moment to show temperature stability. During the test period, temperatures are monitored so that in case of any change, they can be returned to their desired value. When the thickness of ice stops changing, the device is turned off, and the final thickness of the ice is measured. A methyl blue color liquid is used to better observe the ice surface with a meager ratio of $30 \mathrm{cc}$ per 100 liters so that the freezing point of the water does not change. In each experiment, frame-by-frame recorded films are examined, and the thickness of the ice is plotted on a curve in each frame of the note and for each time. The results of the theoretical solution show that the total freezing time is less than 10 minutes, so the freezing of ice thickness is measured at different times. If the ice thickness did not change within 15 minutes, the operation would be stopped. Experiments are repeated with different flow rates and different nozzle distances from the flat plate, and the results are recorded.

\section{Experimental uncertainty}

Note that the mixture of water, ice, and antifreeze keeps the temperature of the refrigerant solution constant, and the temperature of the water supply also keeps constant. The cooling temperature of the copper plate also was completely under control because the heat transfer rate of copper is much higher than in water, and the test time was so long that temperature changes in the copper surface could be ignored. Therefore, the constant temperature of the refrigerant $-18^{\circ} \mathrm{C}$ was approximately the same as the temperature of the copper plate. Previously, in Section 2 , the issue of keeping the refrigerant temperature constant was discussed. The reliability of measurement and calculation is as follows. The sensitivity of the measurement range of the LM35 temperature sensor used for measurement was $\pm 0.1^{\circ} \mathrm{C}$, and it is used to measure the following ranges: $-18^{\circ} \mathrm{C}$ to $0^{\circ} \mathrm{C}$ or $0^{\circ} \mathrm{C}$ to $8.5^{\circ} \mathrm{C}$. Therefore, the accuracy is between $\pm 0.006 \%$ and $\pm 0.012 \%$, respectively. Note that the LM35
Table 2. Results of the uncertainty measurement.

\begin{tabular}{cc}
\hline Variable & Uncertainty (\%) \\
\hline Plate temperature $\left({ }^{\circ} \mathrm{C}\right)$ & 0.6 \\
Water temperature $\left({ }^{\circ} \mathrm{C}\right)$ & 1.2 \\
Time $(\mathrm{s})$ & After a few moments: 0.04 \\
Thickness $(\mathrm{mm})$ & 0.5 \\
\hline
\end{tabular}

temperature sensors are projected and implemented at the nearest distance with the maximum contact coefficient to maximize its speed and accuracy. The diameter tolerance of the sensor pod was less than 0.05 $\mathrm{mm}$. The sensor with greater force is placed inside the pod. Also, silicon paste has been used to fill the probable pores between the pods and the sensor. Generally, in the case of unsteady heat transfer, a contact coefficient affects the heat transfer. Since the processing time was long (about $15 \mathrm{~min}$ ), we dealed with a quasi-steady equilibrium process, so except in the early moments, there was no need to calculate this error. The answers are not acceptable for the first few seconds of starting.

The error caused by the time measuring device is also less than 0.004 seconds ( 250 frames per second). This device has different errors in the different process stages. Initially it has very high error, and after a few moments, its errors approach to zero. Therefore, the error of the time measuring is only significant at the beginning of the process. The data of these initial moments will not be considered due to the high error.

The ice thickness is measured by magnifying the recorded images at any time and transferring them to AutoCAD (AutoCAD is a commercial ComputerAided Design (CAD) and drafting software application, developed and marketed by Autodesk.) software. The measurement error is approximately less than $0.01 \mathrm{~mm}$. Given that the final thickness of the ice is $2 \mathrm{~mm}$, the measurement error will be 0.005. Although AutoCAD has a certain image resolution (pixels), the magnification is so high that there is no need to consider its error. In addition, the ambient air temperature is stabilized at the water temperature $\left(9^{\circ} \mathrm{C}\right)$ to minimize the heat loss from the water to the ambient air. Note that the all errors are linear and do not affect each other. All significant errors are summarized in Table 2.

\section{Problem formulation in numerical solution}

The governing equations of flow and heat transfer in cylindrical coordinates (for Newtonian, viscous, incompressible, and unsteady flow) are as follows:

$$
\begin{aligned}
& \text { Mass: } \\
& \qquad \frac{\partial v_{r}}{\partial r}+\frac{v_{r}}{r}+\frac{\partial v_{z}}{\partial z}-0 .
\end{aligned}
$$

Momentum: 


$$
\begin{aligned}
& \frac{\partial v_{r}}{\partial t}+ v_{r} \frac{\partial v_{r}}{\partial r}+v_{z} \frac{\partial v_{r}}{\partial z}=-\frac{1}{\rho} \frac{\partial p}{\partial r} \\
&+\nu\left(\frac{\partial^{2} v_{r}}{\partial r^{2}}+\frac{1}{r} \frac{\partial v_{r}}{\partial r}-\frac{v_{r}}{r^{2}}+\frac{\partial^{2} v_{r}}{\partial z^{2}}\right), \\
& \frac{\partial v_{z}}{\partial t}+v_{r} \frac{\partial v_{z}}{\partial r}+v_{z} \frac{\partial v_{z}}{\partial z}=-\frac{1}{\rho} \frac{\partial p}{\partial z} \\
&+\nu\left(\frac{\partial^{2} v_{z}}{\partial r^{2}}+\frac{1}{r} \frac{\partial v_{z}}{\partial r}+\frac{\partial^{2} v_{z}}{\partial z^{2}}\right) .
\end{aligned}
$$

Unsteady energy equation in the fluid region (dissipation and radiation heat transfer are neglected) reads:

$$
\frac{\partial T}{\partial t}+v_{r} \frac{\partial T}{\partial r}+v_{z} \frac{\partial T}{\partial z}=\alpha_{l}\left(\frac{\partial^{2} T}{\partial r^{2}}+\frac{1}{r} \frac{\partial T}{\partial r}+\frac{\partial^{2} T}{\partial z^{2}}\right)_{(4)}
$$

In solid-phase:

$$
\frac{\partial T}{\partial t}=\alpha_{s}\left(\frac{\partial^{2} T}{\partial r^{2}}+\frac{1}{r} \frac{\partial T}{\partial r}+\frac{\partial^{2} T}{\partial z^{2}}\right) .
$$

With boundary condition at the interface:

$$
\rho h_{l s} \frac{d S(t)}{d t}=k_{s} \frac{\partial T_{s}}{\partial S}-k_{l} \frac{\partial T_{l}}{\partial S} \text {. }
$$

The conductivity and heat capacity coefficient are constant ( $k$ and $c$ respectively) also it is assumed that $\mathrm{du} \approx \operatorname{cdT}$ where $p, \rho, \nu$, and $\alpha$ are the pressure, density, kinematic viscosity, and thermal diffusivity. Also, subscripts $s$ and $l$ denote solid and liquid, respectively.

The numerical solution methods and other boundary conditions of this problem are the same as [24], and the results of this experimental study are compared with [24]. A numerical solution of the water freezing problem in an experimental research scenario is used to verify the result that the far-field water is $9^{\circ} \mathrm{C}$ and the cold plate temperature is $-18^{\circ} \mathrm{C}$.

\section{Validation, presentation of results, and discussion}

First of all, it should be noted that the fluid flow modeled in this experiment can be stagnation flow or impact of a water jet on a flat plate. In the case of water jets, the heat transfer rate varies in different parts of the plate, while only in the stagnation flow, it is the same for the entire surface of the plate. As a result, in the stagnation flow, the ice thickness will be the same. The preliminary results of this experimental study, Figure 2, and measurements of ice thickness at different points show that the thickness of ice is the same across the entire surface of the plate, so the flow in this experimental study is stagnation flow.

Numerical and experimental results are shown in a graph, in Figures 2 and 3 . The numerical

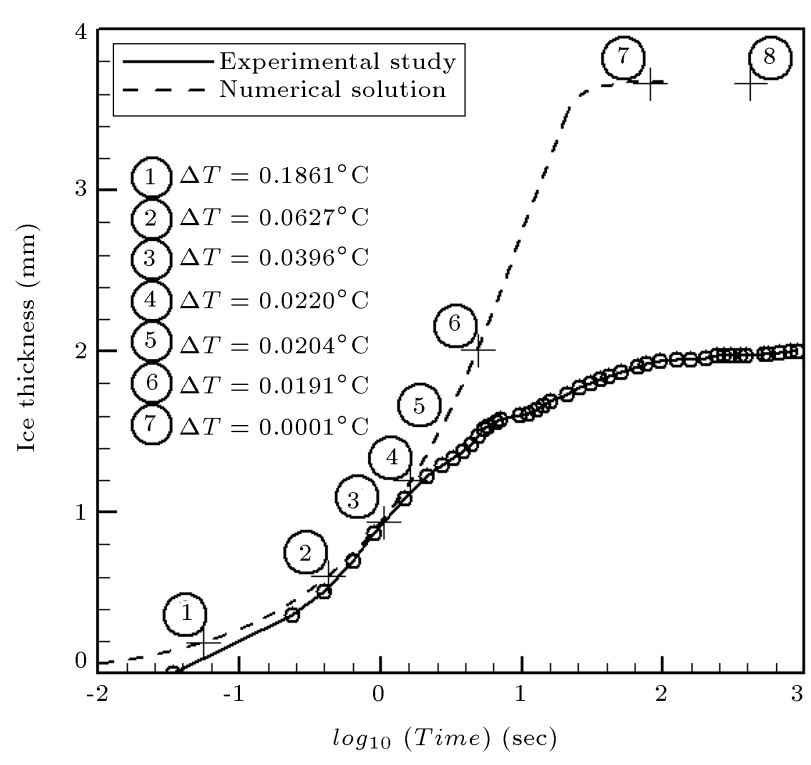

Figure 2. Comparing the numerical and experimental results of evolution of ice thickness versus log (time).

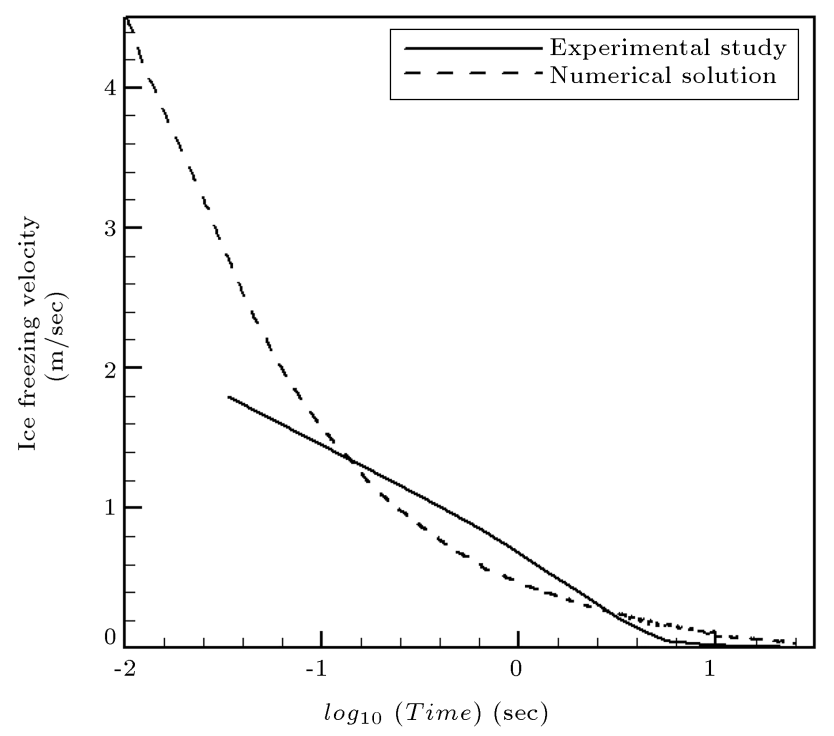

Figure 3. Comparing the numerical and experimental results of freezing velocity of the ice versus log (time).

solution data according to experimental conditions in [24] are used for comparison in these figures. The total results of this laboratory study are also presented in Tables 3-5. As shown in Figure 2, there is a good agreement between numerical and experimental results regarding the ice thickness of $1.2 \mathrm{~mm}$ (point 4 , in numerical solution curve, the time range of 1.6 sec). However, in an area with the thickness more than $1.2 \mathrm{~mm}$, the resulting differences are significant. The cause goes back to the nature of numerical and laboratory work. Over the time, the temperature difference between the bottom of the water and the upper ice level decreases. In the numerical solution, this tiny temperature difference will cause the freezing 
Table 3. Comparison of numerical and experimental solutions in the study of the evolution of ice thickness parameters.

\begin{tabular}{cccccc}
\hline \multirow{2}{*}{$\begin{array}{c}\text { Point no. } \\
\text { (Figure 2) }\end{array}$} & $\begin{array}{c}\boldsymbol{\Delta} \boldsymbol{q} \\
\left(\mathbf{w} / \mathbf{m}^{2}\right)\end{array}$ & $\begin{array}{c}\boldsymbol{\Delta} \boldsymbol{T}_{\mathbf{0}}\left({ }^{\circ} \mathbf{C}\right) \\
\text { in numerical } \\
\text { solution }\end{array}$ & \multicolumn{2}{c}{ Ice thickness $(\mathbf{m m})$} & \\
\cline { 3 - 5 } & & & & & \\
\hline 1 & 1350.1600 & 0.1861 & 0.20 & 0.10 & -1.2440 \\
2 & 91.9520 & 0.0627 & 0.60 & 0.54 & -0.3819 \\
3 & 27.6080 & 0.0396 & 0.94 & 0.94 & 0.0000 \\
4 & 14.9800 & 0.0220 & 1.20 & 1.17 & 0.2130 \\
5 & 8.2637 & 0.0204 & 1.50 & 1.30 & 0.4125 \\
6 & $\mathbf{3 . 4 6 5 0}$ & 0.0191 & 2.00 & 1.50 & 0.6813 \\
7 & 0.0007 & 0.0001 & 3.75 & 1.90 & 1.9101 \\
8 & 0.0000 & 0.0000 & 3.75 & 2.00 & 3.0000 \\
\hline
\end{tabular}

to continue, although this happens at a low rate. As can be seen, in the thickness of approximately $1.2 \mathrm{~mm}$, the temperature difference in the numerical solution is about $0.022^{\circ} \mathrm{C}$ (point 4, in the numerical solution curve). However, the issue of freezing is a topic of interest in numerical and experimental studies. At a thickness of $2 \mathrm{~mm}$, the temperature difference in the numerical solution is $0.019^{\circ} \mathrm{C}$ (point 6). In the experimental study, the freezing has stopped, which is the point of maximum accuracy of laboratory work. That is, we can say that the accuracy of temperature stabilization is $0.019^{\circ} \mathrm{C}$ in the laboratory work. It is noteworthy that the accuracy of the test does not depend on the accuracy of temperature measurement, rather it depends on the measurement accuracy of flow and temperature. Therefore, although the temperature measurement accuracy was less than $\pm 0.1^{\circ} \mathrm{C}$, the working accuracy was higher, lasting to a temperature difference of $0.019^{\circ} \mathrm{C}$.

Another point is that due to the slight temperature difference in a certain area (points 4-6), compared with the numerical solution, the freezing rate in laboratory research is reduced. Therefore the significant difference between the two curves is due to the significant increase in freezing time. If it continues to freeze to a temperature difference of $0.0001^{\circ} \mathrm{C}$ in laboratory work (point 7 in the numerical solution curve), then the final ice thickness is equal in the numerical value and in laboratory work, which is impossible. It could also be interpreted as the freezing point using a heat transfer rate. As seen in Figure 2, freezing is continued to a thickness of $3.75 \mathrm{~mm}$ in the numerical solution. However, when ice thickness reaches $2 \mathrm{~mm}$ (Figure 2, point 6, in numerical solution curve) the net heat flux of the ice surface will be less than $3.5(\mathrm{~W} / \mathrm{m} 2)$. It means that the input heat of the water near the ice is very close to the output heat of water and is not sufficient for freezing the water. In other words, the freezing time increases so much that the amount of heat difference will be smaller than its errors. In these conditions, freezing will practically stop (in the experimental study). Note that $\Delta T$ is the temperature difference between cells of the last row of the ice and the cells of the first row in the water. Also, $\Delta q$ is the difference between the heat input of water near the ice and its output $\left(\mathrm{W} / \mathrm{m}^{2}\right)$ in the numerical solution; however, it can be used as the equivalent temperature and heat input differences for experimental study at any moment.

A comparison between the freezing rates of ice in the experimental study and the numerical solution is shown in Figure 3 . It can be seen that these two curves are seemingly not well-matched on the left side of the curve $(\log ($ Time $)<0)$. Note, in the experimental study, the freezing rates are obtained by dividing the ice thickness by time, which is minimal. In this region. Consequently, the small error in the denominator causes a significant error in calculating the velocity, so the current matching between the two curves is proper. From the curve, it is observed that the speed of ice formation is very high at first, and then, with a steep slope, the speed of ice formation decreases and then stops. As can be seen, although in the numerical solution of freezing the operation continues up to a very small temperature difference between ice and water, in practice, it is not possible.

It is clear that the matching of the experiment flow with the stagnation flow is of particular importance. One of the greatest characteristics of a stagnation flow is the uniform heat transfer within the region of this flow. As a result, the fact that the thickness of the ice is uniform indicates that the flow is close to the stagnation flow. In this study, we used the minimum nozzle distance from the cold plate to find out how close we are to the real stagnation flow. To achieve a better understanding, the freezing of cylindrical stagnation flow is shown in Figures 4 to 6 schematically. Figure 7 shows an image of ice formed at 
Table 4. The results of the experiment in a volume flow rate of $2.7 \mathrm{lit} / \mathrm{min}$.

\begin{tabular}{|c|c|c|c|c|c|c|c|}
\hline $\begin{array}{l}\text { Frame } \\
\text { number }\end{array}$ & $\begin{array}{l}\text { Time } \\
(\mathrm{s})\end{array}$ & $\log _{10}($ Time $)$ & $\begin{array}{c}\text { Ice thickness } \\
(\mathrm{mm})\end{array}$ & $\begin{array}{l}\text { Velocity } \\
(\mathrm{mm} / \mathrm{s})\end{array}$ & $\begin{array}{c}\text { Inlet water } \\
\text { temperature } \\
\left({ }^{\circ} \mathrm{C}\right)\end{array}$ & $\begin{array}{c}\text { Substrate flat } \\
\text { plate temperature } \\
T_{0}\left({ }^{\circ} \mathrm{C}\right)\end{array}$ & $\begin{array}{c}\text { Refrigerant } \\
\text { temperature } \\
\left({ }^{\circ} \mathrm{C}\right)\end{array}$ \\
\hline 1 & 0.0333 & -1.4771 & 0.00 & - & 8.9 & -23.1 & -23.1 \\
\hline 7 & 0.2333 & -0.632 & 0.26 & 1.28571 & 9.0 & -20.1 & -21.0 \\
\hline 12 & 0.4000 & -0.3979 & 0.49 & 1.37143 & 9.0 & -20.1 & -21.0 \\
\hline 19 & 0.6333 & -0.1984 & 0.57 & 0.36735 & 9.0 & -20.1 & -21.0 \\
\hline 27 & 0.9000 & -0.0458 & 1.00 & 1.60714 & 9.0 & -20.1 & -21.0 \\
\hline 44 & 1.4667 & 0.16633 & 1.11 & 0.20168 & 9.0 & -20.0 & -21.0 \\
\hline 64 & 2.1333 & 0.32906 & 1.23 & 0.17143 & 9.0 & -20.0 & -21.0 \\
\hline 82 & 2.7333 & 0.43669 & 1.31 & 0.14286 & 9.0 & -20.1 & -21.0 \\
\hline 98 & 3.2667 & 0.5141 & 1.34 & 0.05357 & 9.0 & -20.1 & -21.0 \\
\hline 115 & 3.8333 & 0.58358 & 1.37 & 0.05042 & 9.0 & -20.0 & -21.0 \\
\hline 130 & 4.3333 & 0.63682 & 1.40 & 0.05714 & 9.0 & -20.0 & -21.0 \\
\hline 147 & 4.9000 & 0.6902 & 1.49 & 0.15126 & 9.0 & -20.1 & -21.0 \\
\hline 162 & 5.4000 & 0.73239 & 1.57 & 0.17143 & 9.0 & -20.1 & -21.0 \\
\hline 173 & 5.7667 & 0.76092 & 1.60 & 0.07792 & 9.0 & -20.0 & -21.0 \\
\hline 195 & 6.5000 & 0.81291 & 1.57 & -0.03900 & 9.0 & -20.1 & -21.0 \\
\hline 211 & 7.0333 & 0.84716 & 1.57 & 0.00000 & 9.0 & -20.1 & -21.0 \\
\hline 289 & 9.6333 & 0.98378 & 1.60 & 0.01099 & 9.0 & -20.0 & -21.0 \\
\hline 335 & 11.1667 & 1.04792 & 1.60 & 0.00000 & 0.9 & -20.1 & -21.0 \\
\hline 384 & 12.8000 & 1.10721 & 1.63 & 0.01749 & 9.0 & -19.6 & -21.0 \\
\hline 427 & 14.2333 & 1.15331 & 1.66 & 0.01993 & 9.0 & -19.6 & -21.0 \\
\hline 472 & 15.7333 & 1.19682 & 1.71 & 0.03810 & 9.0 & -19.6 & -21.0 \\
\hline 622 & 20.7333 & 1.31667 & 1.74 & 0.00571 & 9.0 & -19.7 & -21.0 \\
\hline 772 & 25.7333 & 1.4105 & 1.77 & 0.00571 & 9.0 & -19.8 & -21.0 \\
\hline 922 & 30.7333 & 1.48761 & 1.80 & 0.00571 & 9.0 & -19.9 & -21.0 \\
\hline 1072 & 35.7333 & 1.55307 & 1.83 & 0.00571 & 9.0 & -19.9 & -21.0 \\
\hline 1222 & 40.7333 & 1.60995 & 1.86 & 0.00571 & 8.9 & -19.9 & -21.0 \\
\hline 1525 & 50.8333 & 1.70615 & 1.86 & 0.00000 & 8.9 & -19.8 & -21.0 \\
\hline 1975 & 65.8333 & 1.81845 & 1.91 & 0.00381 & 9.0 & -19.8 & -21.0 \\
\hline 2277 & 75.9000 & 1.88024 & 1.94 & 0.00284 & 9.0 & -19.8 & -21.0 \\
\hline 2877 & 95.9000 & 1.98182 & 1.94 & 0.00000 & 9.0 & -19.7 & -21.0 \\
\hline 3777 & 125.9000 & 2.10003 & 1.94 & 0.00000 & 9.0 & -19.5 & -21.0 \\
\hline 4677 & 155.9000 & 2.19285 & 1.97 & 0.00095 & 9.1 & -19.5 & -19.8 \\
\hline 6029 & 200.9670 & 2.30312 & 1.94 & -0.00060 & 9.1 & -19.6 & -19.8 \\
\hline 7229 & 240.9670 & 2.38196 & 1.97 & 0.00071 & 9.2 & -19.7 & -19.8 \\
\hline 8131 & 271.0330 & 2.43302 & 2.00 & 0.00095 & 9.2 & -19.9 & -19.8 \\
\hline 9031 & 301.0330 & 2.47861 & 1.97 & -0.00100 & 9.3 & -19.9 & -19.8 \\
\hline 10534 & 351.1330 & 2.54547 & 1.97 & 0.00000 & 9.2 & -19.8 & -19.8 \\
\hline 11490 & 383.0000 & 2.5832 & 1.97 & 0.00000 & 9.3 & -19.9 & -21.0 \\
\hline 15653 & 521.7670 & 2.71748 & 2.00 & 0.00021 & 9.3 & -20.0 & -21.0 \\
\hline 16512 & 550.4000 & 2.74068 & 1.97 & -0.00100 & 9.3 & -20.1 & -21.0 \\
\hline 19748 & 658.2670 & 2.8184 & 2.00 & 0.00026 & 9.2 & -20.0 & -21.0 \\
\hline 24041 & 801.3670 & 2.90383 & 2.00 & 0.00000 & 9.2 & -20.1 & -21.0 \\
\hline 27025 & 900.8330 & 2.95464 & 2.00 & 0.00000 & 9.2 & -20.2 & -20.9 \\
\hline
\end{tabular}


Table 5. The thickness of the ice formed in terms of flow rate and nozzle distance from the substrate cold plate.

\begin{tabular}{ccccccc}
\hline $\begin{array}{c}\text { Test } \\
\text { no. }\end{array}$ & $\begin{array}{c}\text { Nozzle distance } \\
\text { from substrate } \\
(\mathbf{m m})\end{array}$ & $\begin{array}{c}\text { Flow rate } \\
(\mathbf{l i t} / \mathbf{m i n})\end{array}$ & $\begin{array}{c}\text { Strain } \\
\mathbf{( 1 / S )}\end{array}$ & $\begin{array}{c}\text { Maximum ice } \\
\text { thickness, } \\
\boldsymbol{S}_{\text {max }}(\mathbf{m m})\end{array}$ & $\begin{array}{c}\text { Substrate flat } \\
\text { plate temperature, } \\
\boldsymbol{T}_{\mathbf{0}}\left({ }^{\circ} \mathbf{C}\right)\end{array}$ & $\begin{array}{c}\text { Water temperature, } \\
\boldsymbol{T}_{\boldsymbol{I}}\end{array}$ \\
\hline 1 & 8 & 2.7 & 8.57 & 2.0 & -19.7 & 9.1 \\
2 & 8 & 3.5 & 18.36 & 2.0 & -19.3 & 8.5 \\
3 & 8 & 4.2 & 26.06 & 1.8 & -19.0 & 8.2 \\
4 & 8 & 4.4 & 27.97 & 1.7 & -19.0 & 8.4 \\
5 & 10 & 4.4 & 23.60 & 2.2 & -19.8 & 8.3 \\
6 & 10 & 4.5 & 18.59 & 2.1 & -19.6 & 8.5 \\
7 & 10 & 5.1 & 23.86 & 2.0 & -19.0 & 8.4 \\
8 & 10 & 6.8 & 38.50 & 1.8 & -18.5 & 8.4 \\
9 & 13 & 4.0 & 6.49 & 2.4 & -19.8 & 9.1 \\
10 & 13 & 5.0 & 11.51 & 2.2 & -19.9 & 8.7 \\
11 & 13 & 5.4 & 14.02 & 2.0 & -18.6 & 7.9 \\
13 & 13 & 6.1 & 18.69 & 2.0 & -19.8 & 8.2 \\
\hline
\end{tabular}

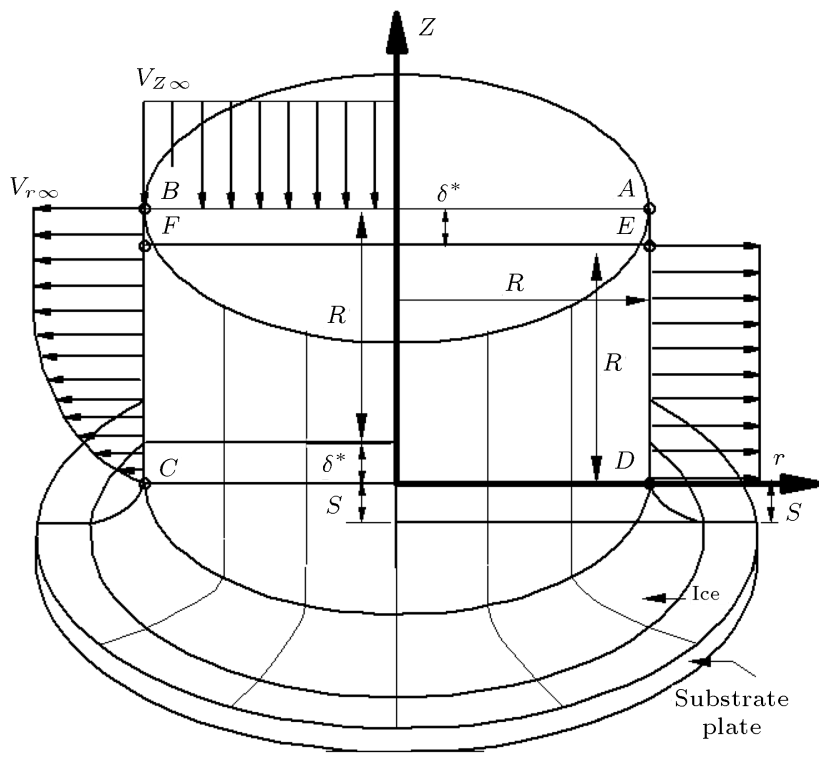

Figure 4. Cylindrical stagnation flow.

a suitable distance from the nozzle to the plate. When the distance from the nozzle to the substrate plate is not enough, only a part of the circular cross section of the nozzle output flow forms a stagnation flow, which can be seen in Figure 8, as the same KLMN region in Figure 6 . To ensure that the entire cylinder is located in the radius $R$ (ABCD region in Figures 4 and 5) and resides in the stagnation flow region, a minimum distance between the nozzle and the coolant surface is required. In Figures 4 and $5, \delta^{*}$ is the thickness of the viscous layer displacement, and in the potential flow, $\delta^{*}=0$. In this case, distance between the nozzle and cooling plate should be at least: $D_{\min }=R+\delta^{*}$ (Figure 5); otherwise, the stagnation flow region would

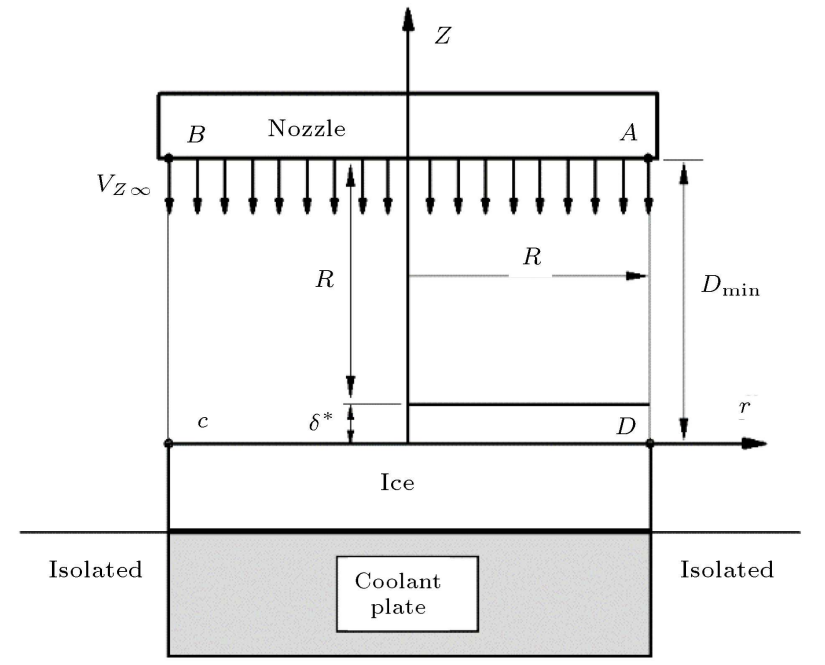

Figure 5. Required minimum distance between the plate and the nozzle outlet $\left(D_{\min }\right)$ in the entire region of stagnation flow $(R)$.

be limited to KLMN region (Figure 6) with a radius $R^{\prime}$. So the thickness of ice outside the KLMN region is not the same as inside that region.

Therefore, the constant ice thickness itself is a reason for the existence of a stagnation flow region (Figures 5 and 7 , vice versa). In accordance to the conditions of this experiment, if the thickness of the ice changes at the edges, we are outside the stagnation flow area, as shown in Figures 6 and 8 (i.e., the distance between the nozzle and the plate is too low). The relation $D_{\text {min }}=R+\delta^{*}$, which defines the viscous stagnation flow region, is confirmed using the experimental method. A value of approximately $2.5 \mathrm{~mm}$ was obtained for the first test. 


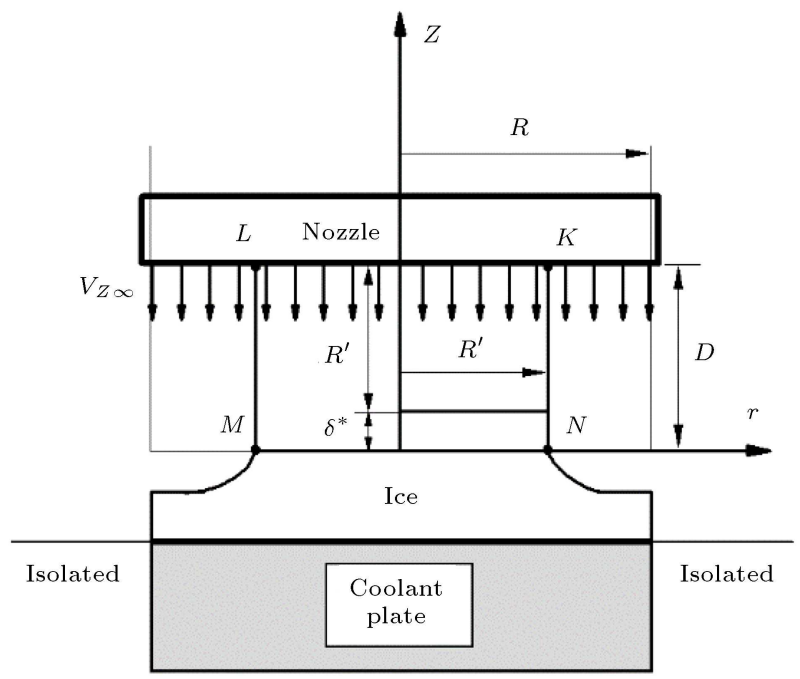

Figure 6. Formation of ice when the distance between the plate and the nozzle outlet $(D)$ is less than the minimum distance required for the entire region of stagnation flow.

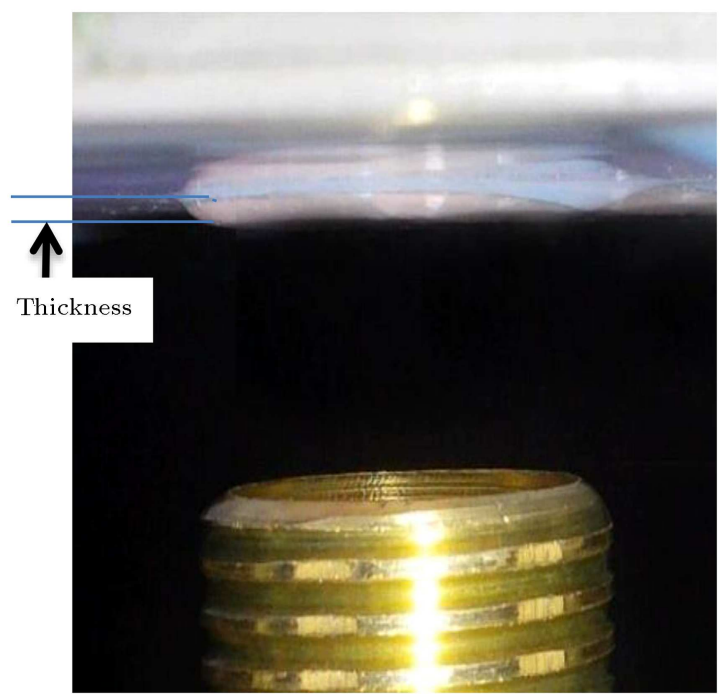

Figure 7. The image of formed ice when the required minimum distance to the plate has been considered. According to Figure 5, the thickness of the ice is the same across its entire surface.

$$
\delta^{*}=D_{\min }-R .
$$

As shown in Figure 6, the thickness of ice is not the same across its entire surface. The stages of ice growth for different distances from the nozzle to the cooling plate are shown in Figure 9. One of these distances is $D=8 \mathrm{~mm}$ less than the minimum distance needed to complete the stagnation flow region (related to $R=8 \mathrm{~mm}$ ). As can be seen, the graphs match each other with a maximum error of $\pm 3.5 \%$. Of course, curve $D=8 \mathrm{~mm}$ is between the curves $D=10.5 \mathrm{~mm}$ and $D=13 \mathrm{~mm}$ in the last steps, which indicates the error in the test. This error is due to the nature of the test; however, the heat transfer across the surface of

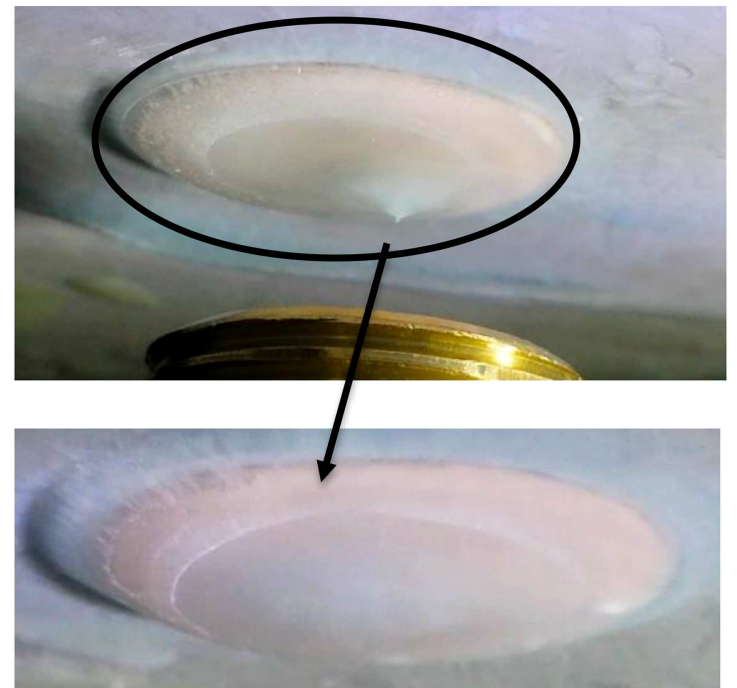

Figure 8. The image of formed ice when the required minimum distance to the plate has not been considered.

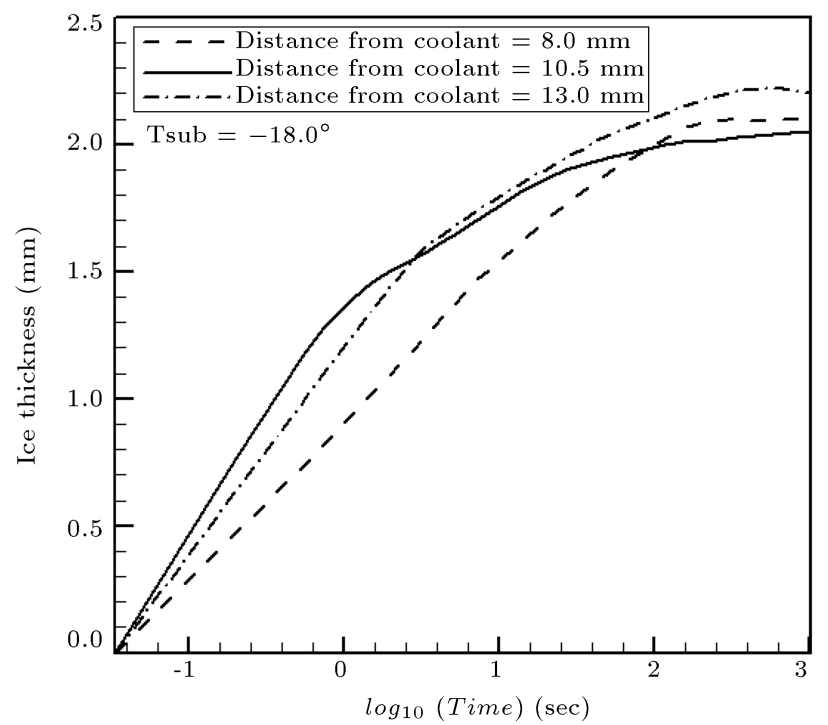

Figure 9. Evolution of ice formation for different nozzle distances to the cold plate (the flow rates are all the same).

the cold plate in a laminar or turbulent flow must be the same. Therefore, the important point is that the final thickness of all distances is the same; because the viscous layer has a constant thickness in a stagnation flow. The final thickness of ice versus strain variation is shown in Figure 10. As is clear from figure, the thickness of ice in the first part of the curve is almost constant, then decreases with a relatively steep slope, and then returns to a constant thickness. However, according to numerical calculations, strain should not affect the heat transfer and freezing of water. So, this steep slope seems to be the result of a transition from a laminar to a turbulent flow. As the strain increases and extends to the turbulent flow region, the thickness of the ice becomes constant again. Because there is no 


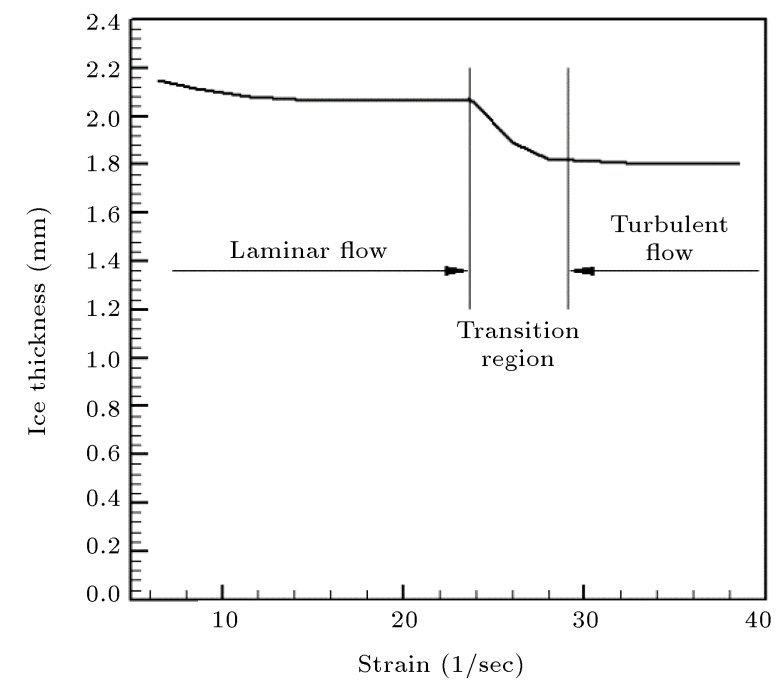

Figure 10. Smoothed curve of the formed ice thickness versus variation of fluid strain.

particular definition for laminar and turbulent regimes in stagnation flow, this test can also be performed to define such regimes. The strain can be obtained by dividing the velocity of water at nozzle output by $R$. The velocity is also obtained by flow rate in each condition. The flow rate is measured by a flow meter in liter/min before the test.

\section{Conclusion}

In the present paper, an experimental study of freezing in axisymmetric stagnation flow has been investigated. Water impinged vertically on a flat plate and freezed due to the low temperature of the flat plate. To perform the test, a device has been prepared that includes a cold substrate plate with a circular cross section. Experiments are carried out on different strains and various distances between the water output section and the cold plate. The comparison of the results of this study with numerical solutions shows reasonable and acceptable convergence in the middle of the diagram. Observations show that at first, water starts to freeze rapidly, and then the rate of freezing gradually decreases and gradually stops. The difference between the experimental and numerical solutions increased gradually by the increase in ice thickness, because in the experimental study, the freezing rate dropped sharply by reducing the temperature difference between the ice surface and its adjacent water body to about $0.022^{\circ} \mathrm{C}$. Then, at a temperature difference of $0.019^{\circ} \mathrm{C}$, freezing has practically stopped. In other words, in this case, the low difference between the heat input of the water layer near the ice and its output is smaller than its error. So, we can say that the accuracy of temperature stabilization in this experiment is $0.019^{\circ} \mathrm{C}$. However, in the numerical solution, the freezing continues to reach $0.0001^{\circ} \mathrm{C}$ with the smallest difference, which results in a significant difference in the latter half of the two freezing curves. It shows that the continuous freezing observed in the theoretical solution is impossible in practice for small temperature differences.

As a result, in practice, changes in the thickness of ice indicate a transition to other regimes such as transition from laminar to turbulent flow. Therefore, a particular definition of the flow regimes (laminar, turbulent, or transitional) during the stagnation flow is provided. Interestingly, according to the results, the thickness of ice in the laminar flow is more than a turbulent flow.

\section{Nomenclature}

$D$

$h$

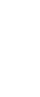

$k \quad$ Thermal conductivity of the fluid

$$
\left(\frac{\mathrm{W}}{\mathrm{m} \cdot \mathrm{K}}\right)
$$

$p \quad$ Pressure $(\mathrm{Pa})$

$R \quad$ Internal radius of nozzle outlet $(\mathrm{mm})$

$S \quad$ Ice thickness (mm)

$t \quad$ Time (s)

$T \quad$ Temperature $\left({ }^{\circ} \mathrm{C}\right)$

$v_{r}, v_{z} \quad$ Velocity components near the plate in $r, z$ directions $\left(\frac{\mathrm{m}}{\mathrm{s}}\right)$

$r, z \quad$ Axisymmetric cylindrical coordinates

$\Delta q \quad$ Difference in the heat input to the water near the ice and its output $\left(\frac{\mathrm{W}}{\mathrm{m}^{2}}\right)$

$\delta^{*} \quad$ Thickness of viscous layer displacement $(\mathrm{mm})$

\section{Subscripts}

$\infty \quad$ Far field

$l \quad$ Liquid phase

ls Liquid to solid (phase change)

$s \quad$ Solid phase

sub Substrate cold plate

\section{References}

1. Stefan, J. "About the theory of ice formation, in particular on the ice formation in polar seas", (Uber die theorie der eisbildung, insbesondere uber die eisbildung in polarmaere), A. Phys. Chem., 42, pp. 269-286 (1891).

2. Goodrich, L.E. "Efficient numerical technique for one dimensional thermal problems with phase change", Int. Journal of Heat Mass Transfer, 21, pp. 615-621 (1978). 
3. Sparrow, E.M., Ramsey, J.W., and Harris, J.S. "The transition from natural convection controlled freezing to conduction controlled freezing", Journal of Heat Transfer, 103, pp. 7-13 (1983).

4. Lacroix, M. "Computation of heat transfer during melting of a pure substance from an isothermal wall", Numer. Heat Transfer B, 15, pp. 191-210 (1989).

5. Yeoh, G.H., Behnia, M., De Vah Davis, G., et al. “A numerical study of three-dimensional natural convection during freezing of water", Int. J. Numer. Mech. Engng., 30, pp. 899-914 (1990).

6. Hadji, L. and Schell, M. "Interfacial pattern formation in the presence of solidification and thermal convection", Phy., Rev. A, 41, pp. 863-873 (1990).

7. Hanumanth, G.S. "Solidification in the presence of natural convection", Int, Comm. Heat Mass Transfer, 17, pp. 283-292 (1990).

8. Oldenburg, C.M. and Spera, F.J. "Hybrid model for solidification and convection", Numer, Heat Transfer $B$, 21, pp. 217-229 (1992).

9. Trapaga, G., Matthys, E.F., Valecia, J.J., et al. "Fluid flow, heat transfer and solidification of molten metal droplets impinging on substrates: comparison of numerical and experimental results", Metall. Trans. B, 23B, pp. 701-718 (1992).

10. Watanabe, T.I., Kuribayashi, I., Honda, T., and Kanzawa, A. "Deformation and solidification of a droplet on a cold substrate", Cham. Engng, 47, pp. 3059-3065 (1992).

11. Marchi, C.S., Liu, H., Lavernia, E.J., et al. "Numerical analysis of the deformation and solidification of a single droplet impinging on to a flat substrate", Journal Mater, 28, pp. 3313-3321 (1993).

12. Weidman, P.D. and Mahalingam, S. "Axisymmetric stagnation-point flow impinging on a transversely oscillating plate with suction", J. Engineering Mathematics, 31, pp. 305-318 (1997).

13. Shokrgozar Abbasi, A. and Rahimi, A.B. "Nonaxisymmetric three-dimensional stagnation-point flow and heat transfer on a flat plate", Trans. ASME J. Fluids Engineering, 131(7), 074501-074505 (2009).

14. Shokrgozar Abbasi, A. and Rahimi, A.B. "Threedimensional stagnation-point flow and heat transfer on a flat plate with transpiration", J. Thermophys. Heat Transfer, 23(3), pp. 513-521 (2009).

15. Shokrgozar Abbasi, A., Rahimi, A.B., and Niazmand, H. "Exact solution of three-dimensional unsteady stagnation flow on a heated plate", J. Thermophys. Heat Transfer, 25(1), pp. 55-58 (2011).

16. Shokrgozar Abbasi, A. and Rahimi, A.B. "Investigation of two-dimensional unsteady stagnation flow and heat transfer impinging on an accelerated flat plate", Trans. ASME J. Heat Transfer, 134(6), 064501064505 (2012).

17. Shokrgozar Abbasi, A., Rahimi A.B., and Mozayyeni, H. "Investigation of three-dimensional axisymmetric unsteady stagnation-point flow and heat transfer impinging on an accelerated flat plate", J. Applied Fluid Mechanics (JAFM), 9(1), pp. 451-461 (2016).

18. Brattkus, K. and Davis, S.H. "Flow induced morphological instabilities: stagnation-point flows", Journal of Crystal Growth, 89, pp. 423-427 (1988).

19. Rangel, R.H. and Bian, X. "The inviscid stagnationflow solidification problem", Int. Journal of Heat Mass Transfer, 39(8), pp. 1591-1602 (1994).

20. Lambert, R.H. and Rangel, R.H. "Solidification of a supercooled liquid in stagnation-point flow", Int. Journal of Heat Mass Transfer, 46, pp. 4013-4021 (2003).

21. Yoo, J.S. "Effect of viscous plane stagnation flow on the freezing of fluid", Int. Journal of Heat and Fluid Flow, 121, pp. 735-739 (2000).

22. Shokrgozar Abbasi, A. and Rahimi, A.B. "Solidification of two-dimensional viscous, incompressible stagnation flow", Int. Journal of Heat Transfer, 135, 072301-072308 (2013).

23. Shokrgozar Abbasi, A. "Three-dimensional axisymmetric solidification of a viscous incompressible flow in the stagnation point region", J. Applied Fluid Mechanics (JAFM), 10(1), pp. 413-420 (2017).

24. Alizadeh, R., Rahimi, A.B., and Najafi, M. "Nonaxisymmetric stagnation-point flow and heat transfer of a viscous fluid on a stationary cylinder", Scientia Iranica, B, 23(5), pp. 2238-2246 (2016).

25. Adil, M.S. "MHD stagnation point flow of nanofluid on a plate with anisotropic slip", Symmetry, 11(2), p. 132 (2019).

26. Imtiaz, M., Nazar, H., Hayat, T., et al. "Effect of porous medium in stagnation point flow of ferrofluid due to a variable convected thicked sheet", J. Heat Transfer, 141(11), pp. 112602-112611 (2019).

27. Rahimi, A.B. and Mozayeni, H. "Similarity solutions of axisymmetric stagnation-point flow and heat transfer of a viscous, boussinesq-related density fluid on a moving flat plate", Scientia Iranica, B, 21(4), pp. 1440-1450 (2018).

28. Waini, I., Ishak, A., and Pop, I. "Hybrid nanofluid flow towards a stagnation point on a stretching/shrinking cylinder", Scientific Reports, 10, p. 9296 (2020).

29. Shokrgozar Abbasi, A. and Ghayeni, M. "Water vapor solidification of saturated air in two-dimensional stagnation flow", Journal of Mechanical Engineering, Transaction of Scientia Iranica, B, 27(2), pp. 693-703 (2020).

30. Narender, G., Govardhan, K., and Sreedhar, G.S. "Magnetohydrodynamic stagnation point on a Casson nanofluid flow over a radially stretching sheet", Beilstein J. Nanotechnol, 11, pp. 1303-1315 (2020).

31. Maqbool, R., Ijaz, M.K., Qayyum, S., et al. "Numerical modeling and MHD stagnation point flow of ferrofluid (non-Newtonian) with Ohmic heating and viscous dissipation", International Journal of Modern Physics B, 34(28), 2050265 (2020). 


\section{Biographies}

Ali Shokrgozar Abbasi, born in 1970, received his $\mathrm{PhD}$ from Mechanical Engineering Department, Ferdowsi University of Mashhad, Iran in 2010. His field of study is solidification in stagnation flow. During his $\mathrm{PhD}$ program, he established a three-dimensional computer program to predict the flow, temperature, and solidification of a fluid in stagnation flow. In 2011, he joined Payam Noor University of Mashhad as an Assistant Professor, teaching primarily CFD, advanced heat transfer, advanced numerical calculations, and engineering mathematics. He works on techniques of modeling process in heat and fluid flow with phase change in computer programs. His works include ana- lytical and experimental methods. His main interests are solidification, phase change to liquid, heat, and fluid flow. He has already published about 12 international journal papers (ISI) and a book "Convective heat transfer".

Mojtaba Najafian was born in Naeen, Iran in 1983. He received a BSc degree in Mechanical Engineering from Ferdowsi University of Mashhad, Iran in 2006 and his MSc degree in Energy Conversion from Payame Noor University of Mashhad, Iran in 2016. His main research interests include energy, combustion and air conditioning fluid dynamics, and aerodynamics. He has already published six papers in conferences and three journal papers. 